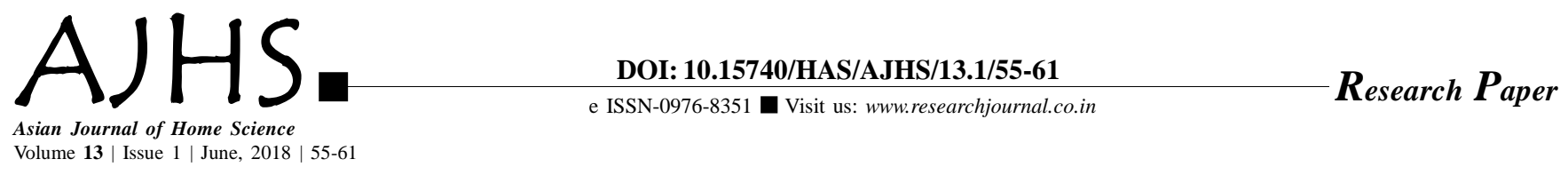

\title{
Breastfeeding knowledge, attitude and practices: A comparative study of urban and rural mothers in northern Karnataka, India
}

Muktamath U. Vinutha, Itagi Sunanda and Khadi B. Pushpa

Received: 29.12.2017; Revised: 18.03.2018; Accepted: 04.04.2018

See end of the paper for authors' affiliations

\section{Muktamath U. Vinutha}

Krishi Vigyan Kendra, University of Agricultural Sciences, Dharwad

(Karnataka) India

Email : vinumuktamath@gmail. com
ABSTRACT : The pattern of infant and young child feeding that provides the most benefit includes being put to the breast within an hour of birth, exclusive breastfeeding for 6 months, continued breastfeeding along with complementary foods upto 2 years of age or beyond and avoidance of any prelacteal feeds and bottle feeding. In India, breastfeeding is culturally well accepted but inadequately practiced, partly due to ignorance and taboos that significantly contribute to undesirable breastfeeding practices such as delayed initiation and discarding of colostrum. In this context a cross-sectional study was conducted with the objective to find the "Breastfeeding knowledge, attitude and practices: A comparative study of urban and rural mothers in northern Karnataka, India" in northern Karnataka. The population of the study consisted of mother -infant dyads, where the infants were in the age group of 3- 24 months and their mothers. The sample comprised of 900 women of whom 600 were from rural area and 100 from urban area. The tools used for the study were socio - economic status (SES) scale developed by Aggarwal et al. (2005), a self structured questionnaire to study feeding practices and knowledge of mothers towards breastfeeding and Iowa Infant Feeding Attitude Scale (1999) to assess maternal attitude towards infant feeding. The results indicated that rural mothers practiced early initiation of breastfeeding, exclusive breastfeeding for first six months and longer duration of breastfeeding when compared with urban mothers. The rate of not feeding colostrum was high in urban area $(37.33 \%)$ when compared to rural mothers $(21.83 \%)$. Urban mothers had high knowledge regarding breastfeeding compared with rural mothers. However, rural mothers had more favorable attitude towards breastfeeding when compared with urban mothers.

KEY WORDS: Exclusive breastfeeding, Colostrum, SES, Knowledge, Attitude

- HOW TO CITE THIS PAPER : Vinutha, Muktamath U., Sunanda, Itagi and Pushpa, Khadi B. (2018). Breastfeeding knowledge, attitude and practices: A comparative study of urban and rural mothers in northern Karnataka, India. Asian J. Home Sci., 13 (1) : 55-61, DOI: 10.15740/HAS/AJHS/13.1/55-61. Copyright@ 2018: Hind Agri-Horticultural Society. 